\section{Resenha bibliográfica}

Schonberger, Richard J. World class manufacturing - the lessons of simplicity applied. New York, The Free Press/Macmillan, 1986.

World class manufacturing - the lessons of simplicity applied ef uma continuação do primeiro livro de $R$ i. chard Shounberger, Japanese manufacturing techniques: nine hiolden Jessons in simplicity, traduzido para - português como Técnicas industriais japonesas: nove liçōes ocultas sobre simplicidade.

A engenharia industrial enrique. ceu-se muito com as técnicas apresentadas no livro. Baseada nelas, a indústria japonesa deu um grande salto, passando a apresentar produtos que dominaram seus concorrentes estrangeiros. Na realidade, a filosofia que está por trấs dessas técnicas ê muito simples. Fabricar bem da pri. meira vez, para evitar refugos posteriormente. Para que isto se realize, o produto deverá ser controlado o mais próximo possivel da operação que - fabricou. Por que não controlar, portanto, o proprio processo? Uma vez que existe a certeza de que serão fabricadas tantas peças boas quantas necessárias, torna-se inútil geral estoques no processo. Sem estoques de processo, a ấrea necessária diminui, assim como inúmeros equipamentos de manuseio. Porém, como garantír que o equipamento funcione bem e sem parar no perfodo previsto? Pro. cedendo a uma manutençẫo preventiva e flexibilizando as máquinas. Para reduzir a probabilidade de acontecerem problemas na fabricaçăo que sejarn resultantes do projeto, equipes conjuntas de pessoal da área comercial, de projetos e de fabricação deverão ser formadas a fim de discutirem os problemas potenciais e evitaremnos dali para a frente.

Estendendo a mesma linha de pensamento, por que não envolver os fornecedores, os transportadores e os proprios clientes? Desta forma, procedeu-se a uma revolução na adminis tração da produçãa.

Na realidade, comparando-se o sistema tradicional com o Worid class manufacturing, houve apenas a mudança na org̣anizaçã̃o e na atribuição das pessoas, para que todos estivessem realmente envolvidos na fabricaçăo, principalmente os departamen. tos de apoio como manutenção, engenharia industrial, controle de qualidade, engenharia de processo e de produto. O número de niveis hierár. quicos reduziu-se e cada item produzido passou a ter a real atençẩo de todos os envolvidos.

Na verdade, as modificaçães acima foram suficientes para reduzir a proporção de pecas defeituosas em 10 vezes; tempos de passagem de fabricação, em 20 vezes; estoques em processo, de 21 dias para um; ou, ainda, triplicar volumes de vendas com a metade do espaço.

Os brilhantes resultados consegui. dos por essas téenicas garantiram o sucesso do livro em questäo. Na verdade, existe farta literatura sobre Controle de Qualidade Total (COT), Sistemas Just in Time (JIT), ou, ainda, Tecnologia de Grupo, porém cada um tratando de seu assunto isoladamente, e com certa complexidade a aridez.

$O$ mérito de R. Schonberger foi reunir toda a literatura, analisar o impacto das varias abordagens em conjunto e transmiti-las de maneira simples, dando ainda exemplos concretos em. empresas norte-americanas. mostrando que fora do Japão também é possível conseguir bons resultados.

A organização dos capítulos ê feita de forma didática, mostrando cada aspecto em separado e interligando-se no fim.

Segue um resumo dos 13 capínlos do livro que está sendo traduzido para o português e editado pela Pio. neira.
Capitulo 1-Mais rápido, mais alto, mais forte

Conta como vem sendo a fabrica. ção tradicional com os seus vicios a dificuldades. Comenta, ainda, como foi o ponto de virada em que algumas empresas reagiram e obtiveram seus primeiros resultados.

A fillosofia do World class manufacturing (Fabricaçăo classe universal) está resumidamente exposta neste capítulo, e lembra muito o seu título.

\section{Capítulo 2 - Operadores de linha} e dados das operaçöes

Como o anterior, este capitulo também trata de filosofia e mudança na cultura da empresa. Para que uma fábrica se torne de classe universal, deve haver um envolvimento maciço nos problemas que os operadores enfrentam a cada minuto no local de trabalho.

A atividade de coletar informa. cơes, analisálas e solucionar problemas torna-se primordial, sem o que a prơuçẫo năo garantirá produçốes sem paradas ou problemas de qualidade. A pessoa mais adequada para esta atividade é o próprio operador. R. Schonberger mostra como conseguir tal resultado, utilizando controle estatístico do processo, mantendo as. ferramentas e os calibradores limpos e, principalmente, provendo um bom gerenciamento. 0 autor dá exemplos de bom gerenciamento com suas implicações e conseqŭências.

\section{Capitulo 3 -Departamentos} auxiliares como atores coadjuvantes

Os componentes destes departamentos devem localizar-se no piso da fábrica, onde os problemas acontecem e, mais ainda, garantindo um bom relacionamento entre eles e o pessoal da produção.

A manutenção torna-se mais eficiente com menos gente no departamento de manutençẫo da fábrica. Pouco a pouco, os operadores lubrificam seus proprios equipamentos e aprendem a fazer a regulagem $e$ os reparos simples; começam, em suma, a sentir um senso de propriedade quanto ao equipamento.

Com menos gente no departamento de qualidade, obtém-se melhor qualidade. Os próprios operadores inspecionam seu trabalho ou o do operador anterior. Discutem-se os problemas surgidos, graças a anotaçôes em quadros. 
A contabilidade de custos torna diretos os custos de departamentos auxiliares, simplificando, assim, a tarefa de calcular os custos.

$O$ controle da produçăo fica facilitado, pois grande parte será visual e os estoques intermediários desaparecem.

Deve haver uma equipe formada com o pessoal de Engenharia Industrial, Compras, Engenharia de Fabricação Engenharia de Projetos. 0 objetivo dela é realizar apenas aque. les trabalhos que acrescentam valor ao produto.

Deve-se lutar para reduzir prazos de toda a natureza, desde o trabalho administrativo até o de produção.

\section{Capitulo 4 - Atuação exagerada do capital}

A automação e sua necessidade são discutidas, e a conclusäo a que cheya R. Schonberger sobre sua vantagem; porém, apenas no caso de melhorar o desempenho. Isto é tam. bếm vallido para os robôs.

Um primeiro ponto para começar sằ os equipamentos que permitem interligar as máquinas utilizadas para um mesmo produto. Na medida em que for necessário ampliar a capacidade, é preferível instalar uma segun. da linha igual à primeira, a ter uma nova que substitua a primeira com velocidade maior.

Uma técnica JIT utilizada para evitar paradas é tornar todos os centros de trabalho em gargalo, para que recebam a atenção necessária. Os operadores devem constituir a primeira linha de ataque aos problemas que surgem quando termina um esto. que de amortecimento causando pa. radas.

R. Schonberger discute o uso de máquinas unitảrias que fazem muitas operaçóes, tanto em oficinas quanto em escritórios.

As conclusões a seguir terminam o capitulo:

- A mão-de-obra é muito valiosa, anquanto equipamentos não pensam nem resolvem problemas. Equipamentos devem ser introduzidos apenas quando há realmente uma vantagem calculada.

- Os equipamentos apresentam, so. bre as pessoas, a vantagem de menor variabilidade: movimentos, tempos, ciclos e qualidade uniformes.
Capítulo 5 - Economia de múltiplos

No passado, a questão do tamanho das máquinas foi satisfatoriamente resolvida, escolhendo-se a maior máquina do catálago. Porém. outros fatores mostraram-se impor. tantes para serem considerados, como:

- A rapidez com que a máquina pode ser ajustada.

- A facilidade de prover a manutenção a de mantẽ-la produzindo com qualidade.

- A facilidade com que a máquina pode ser movida.

- A facilidade de ajustar a velocidade da máquina de acordo com flutuações da demanda final.

- Preco baixo para que novas unidades possam ser adquiridas com o tem. po, conforme a velocidade do crescimento da demanda.

O autor conclui:

- Varias equipes, células, linhas ou máquinas sấo melhores do que uma, pois duas equipes ou conjuntos de equipamentos, conseguindo 0 mesmo produto ou familia de produtos, estão em uma competição amigável, quando as coisas vẫo bem. Elas se complementam quando ocorre uma queda nas vendas ou quando algo não vai bern.

- Deve-se adicionar capacidade fíxa da mesma maneira que se adicionam pessoas: em pequenos incrementos, à medida que a demanda cresce.

Em virtude do fato de que as máquinas devem ter suas velocidades adaptadas às necessidades, podendo mesmo parar, surge a necessidade de manter-se o operador sempre ocupa. do. Assim, os operadores deveräo ser versáteis, a fim de moverem-se para onde o trabalho estiver.

Quando as máquinas estão pro. ximas entre si, as mudanças nas velo. cidades podem ser comunicadas ao operador anterior pelo próprio sistema de puxar, como o Kanban.

Os conceitos de tornar a produ. ção flexível também são aplicáveis para a movimentação das ma̛quinas. prateleiras móveis, formar cellulas e eliminar sistemas automaticos de estocagem.
Capitulo 6-Centros de responsabilidade

Antigamente, usavam-se os termos fluxo do processo, organizaçăo humana e disposição físiça de maneira independente desordenada. Hoje, usa-se o termo organização da fábrica. É importante criar centros de res. ponsabilidade. Säo analisados seîs tipos de organização de fábricas, dependendo da situaçäo:

- Agrupado desordenado, que o pior tipo, e ocorre em duas situaçōes: em oficina de serviços intermitentes, e no caso de produtos mais padronizados em que houve um crescimento desordenado.

- Linhas de fluxo agrupadas que contêm os equipamentos dispostos de maneira a garantir o fluxo de produ. uão. Pode conter máquinas unitárias.

- Tipo celular, um tipo de agrupamento que fabrica uma família de produtos.

- Estaçăo ou máquina unităria, que executa vắrias operaçốs en série para fabricaçăo de um módulo com. pleto do produto. Ao contrărio das cớlulas, as operaçồ são feitas em uma em vez, de em várias máquinas ou estaçốes.

- Linhas de fluxo dedicadas que são um caso de linhas de fluxo, porém dedicadas para um produto ou uma pequena gama de produtos.

- Tipo combinado, que ocorre num período de transição para mudar a organizaçẫo do tipo agrupado para linhas de fluxo.

Capitula 7 - A qualidade como meta

Foi na década de 80 que as indús. trias ocidentais embarcaram na Quali. dade Total, após uma estagnaçăo de 35 anos.

Um dos pontos fundamentals é controle do processo. Ferramentas uteis para esta finalidade são:

- quadro de fluxo de processo;

- análise de Pareto;

- diagrama de espinha de peixe;

- histogramas;

diagrama de controle de processo. 
O autor dedica um parágrafo as avaliaçóes de fornecedores e auditorias da qualidade.

E analisado, em seguida, o elo entre a qualidade e o JIT, enfatizada, de muitas maneiras, a vantagem de analisar as causas dos defeitos.

E interessante mencionar duas citaçöes: "U um axioma, no controle da qualidade, que o tempo para identificar causas determinâveis dura enquanto essas causas estiverem ativas"; e "o atraso pode ainda significar que a causa do problema e mais difícil de ser identificada e, em muitos casos, impossivel".

A mensagem do cap/tulo pode ser resumida $\mathrm{em}$; a qualidade assunto de todos.

\section{Capitulo 8 - Alavancagem de projetos}

É necessário que o projeto seja voltado ao cliente e intimamente integrado com o resto da organização.

Dois conselhos são dados: minimizar o número de componentes e utilizar projetos modulares: o autor cita văríos exemplos.

Lentamente, devem ser formadas equipes de marketing-projeto-fabricação. Uma das formas e promover a rotação de engenheiros de produto na fabricação, para que possam co. nhecer os problemas práticos de seus projetos.

E importante reduzir o prazo para projetar peças. Tempos de passagem devem ser encurtados um bom exemplo disto é mostrado neste cap $/$ tulo.

Captulo 9 - Companheiros de lucro: fornecedores, transportadores $e$ clientes

Atuaimente, aqueles de quem com. pramos a quem vendemos não po. dem ser concorrentes. Eles são coprodutores, co-fabricantes ou compa. nheíros no lucra.

Os fornecedores devem ser desenvolvidos cuidadosamente. Para isto, devem ser em número reduzido para que mais atenção possa ser dada a cada um. Contrariamente 20 que possa ser esperado, os fornecedores não irấo à falência os resultados abaixo serão atingidos:

- O fornecedor venderá volumes muito maiores para um número multo menor de clientes do que antes.
Contratos de longo prazo substituem pedidos de compra de curto prazo.

- fornecedor recebe treinamento, informaçōes de planejamento avançado ecasionalmente, até ajuda $\mathrm{fl}$. nanceira.

- Alguns contratos podem prever entregas a um ritmo diârio regular, em vez de flutuaçôes, conforme a demanda.

- Compradores da fabrica do cliente assumem a dor de cabeca dos fretes.

Requisitos contratuais devem ser rigidos, obrigando o fornecedor a promover melhoramentos rápida e continuamente.

Os transportadores também foram abordados, e a soluçăo é que se adaptem á rápida carga e descarga, fazendo um roteiro otimizado, servindo a tal número de usuários que lotem as carretas.

\section{Cap/tulo 10 - Modelos simples} sistemas simples

Devemos evitar o uso de modelos complexos, pois nunca funcionam bem, causando frustração, Os engenheiros industriais e o pessoal de gerência parecam felizes em mudtar para módelos visuais e simples que apresentem resultados mais satisfatorios.

Os sistemas simples de informacăo tamberm apresentam dados sobre custos, e nos devemos conhecề-los para estabelecer os preços e tomar decisōes sobre a produção.

No sistema de classe universal, va. rios serviços auxiliares, como qualida* de e manutenção, são feitos por operadores que, juntamente com suas máquinas, estão dispostos de acordo com o fluxo do produto. Existem trabalhos, atualmente, com vistas a abordar criativamente os custos, como, por exemplo, utilizar o tempo de passagem para alocar as despesas indiretas. Essas abordagens têm várias vantagens porque a maioria das des. pesas indiretas globais deve-se ao tempo gasto com demoras problemas que aumentam os tempos de passagem.

Os estoques devem ser gerenciados de maneira simplificada.

As ordens de fabricaçã̄o serăo reduzidas e dirịirão células inteiras, e näo mais máquinas individuais.
O número de relatórios será diminuído, dando mais tempo a cada um para trabalhar.

\section{Captuto 11 - Gerenciando a} transformaçáo

As alterações para transformar uma empresa em classe universal podem ser feitas em curto prazo;

- Basta planejar as acões e começar.

- Não é necessafio esperar longos estudos para provar que os conceitos estẫo certos.

- Os resultados são rápidos e visiveis, convencendo todos.

- Nấo se implicam grandes investimentos.

- Há um entusiasmo e satisfação do pessoal envolvido.

R. Schonberger enumera vários exemplos de implantação e comenta - papel da manutenção preventiva total e do controle da qualidade to. tal, e do JIT, ao fabricante de classe universal.

Cap/tulo 12 - Treinamento: o agente catalisador

O treinamento a melhor forma de íniciar uma implantaçẫo JIT/COT. Poém, necessário envolver o pessoal da produção. Em seguida, só iniciar os projetos-piloto. Um vídeo pode ser mostrado no treinamento; contudo, certamente, deverá ser feito outro para mostrar a que se chegou nos grupos-piloto.

\section{Capitulo 13 - A estratégia revelada}

0 autor elabora uma lista de aça para excelência em fabricação:

- Conheca o cliente.

- Reduza o trabalho em processo.

- Reduza as linhas de fluxo.

- Reduza os tempos de preparo e de ajuste.

- Reduza as distâncias de fluxo e espaco.

- Aumente a freqũência produção/ entrega para cada um dos itens exigidos.

- Reduza o número de fornecedores para apenas alguns poucos e bons.

- Reduza o número de componentes. - Torne a fabricacão do produto facil e sem erros.

- Organize o local de trabalho de modo a eliminar o tempo de busca. 
- Treine seus funcionários para dominarem mais de um trabalho.

- Registre e guarde os dados sobre a produção, qualidade e problemas no local de trabalho.

- Garanta que o pessoal da produção faca a primeira tentativa para resolver os problemas, antes do pessoal dos departamentos auxiliares.

- Mantenha e methore o equipamento o pessoal existentes, antes de pensar a respeito de novos equipamentos.

- Procure um equipamento simples, barato móvel.

- Em lugar de apenas uma, procure ter vátias estaçס̄es de trabalho, má. quinas, células e linhas para cada produto:

- Automatize paulatinamente, quando não houver outra maneira de reduzír a variabilidade do processo.

Diz ainda $R$. Schonberger como dar os primeíros passos em díreçäo a ser um fabricante classe universal.

Em vários dos capítulos, o autor apresenta conceitos exemplos de análise do valor, mencionando-os claramente em alguns, em outros não, preferindo englobálos sob o titulo "Fabricaçåo classe universal".

$\mathrm{Na}$ condiçäo de antigo professor de administração de empresas, o autor mostra seu conhecimento nas vá. rias ấreas que compóem uma empresa, tanto por meio de bibliografia citada - incluindo nela são só disserta. çōes acadêmicas, como artigos em períódicos, além de livros - quanto pela sua prática de consultor.

R. Schonberger conseguiu, nas 253 páginas de seu livro, numa linguagem direta, bastante agressiva, ressaltar as vantagens do World class manufacturing, motivando os leitores diretamente para a ação.

João Mário Csillag Engenheiro gerondutico peto ITA, doutor em administração da empresas peta FGV, protessor na EAESPIFGV cansultor na dre de produtividade.
Seattle (Chefe lindio). Preservaça do meio ambiente - manifesto do Chefe Seattle ao presidente dos EUA. São Paulo, Babel Cultural, $1987.47 \mathrm{p}$. (Trad. Magda Guimarães Khouri Costa.)

A Editora Babel Cultural, no ini cio de suas atividades, acaba de lançar, numa tradução de Magda Guima. rães Khouri Costa e com 20 ilustraçōes de Vera Rodrigues, o Manifesto do Chefe Indio Seattle. Ele escroveu Preservação do meio ambiente em 1855, respondendo à proposta do então presidente dos Estados Unidos da América, Franklin Pearce, que desejava comprar a terra dos índios.

0 editor Sérgio Amad Costa infor. ma, na Apresentaçăo, que o Manifesto foi traduzido da versão original, localizada na Seattie Historical Society, em Washington. Fica-se sabendo, igualmente, que o "chefe Seattle nasceu em 1790 e morreu em 1866. Liderou os Duwamish e as tribos Suquamish, Saminish, Skopamish Stakmish, sendo o primeiro signatá rio do tratado de Port Elliot, pelo qual estas tribos se submeteram às imposiçöes governamentais dos EUA recebendo, em troca, uma reserva indígena. Cumpre lembrar, também, que a cidade de Seattle, nos EUA, tem este nome em homenagem ao chefe dos Duwamish" (p. 5).

Embora escrito há mais de 130 anos, o manifesto é considerado como um dos mais profundos pronunciamentos sobre a defesa do meio ambiente, sendo de uma atualidade indiscutivel. Isto porque chama a atenção para a falta de respeito e de cuidado com a terra e, conseqüentemente, com o equilibrio ecológico.

Seattle começa sua resposta ao Presidente Pearce afirmando que o seu povo irá considerar a proposta recebida para vender mais suas terras, embora se pergunte: "É possivel comprar ou vender o céu o calor da terra? Tal iđếia é estranha para nós. Se nẫo possuímos o frescor do ar e o brilho da água, como podem com. prá-los? Cada pedaço desta terra é sagrada para o meu povo. Cada ramo brilhante de um pinheiro, cada areia da praia, cada bruma nas densas florestas, cada clareira e cada inseto a zumbir são sagrados na memória do meu povo. A seiva que corre através das árvores carrega as memórias do homem vermetho $(.$.$) . Somos parte$ da terra e ela é parte de nós (...). Deste modo, quando o grande Chefe manda dizer que quer comprar nossa terra, ele pede muito de nós (...). Consideraremos sua oferta de comprar nossa terra. Mas não será fácill, pois esta terra sagrada para nos" $(p$. 11,13 e 15 ).

Em sua sabedoria, o Chefe Seattle da conselhos ao homem branco, lem. brando que deve ensinar às crianças que "os rios são nossos irmãos", que "a terra é nossa mãe". Assim, "tudo - que ocorrer com a terra ocorrerá aos filhos da terra. Se os homens desprezam o solo, estâo desprezando a \$i mesmos (...). O que ocorrer com a terra recairá sobre os filhos da terra. O homem nấo teceu a trama da vida; ele es meramente um de seus fios. Tudo o que fizer ao tecido fará a si mesmo" (p. 19, 35 e 39 ).

Nos dias de hoje, observa-se uma série de modismos envolvendo a questão ecológica, com partidos poli"ticos a grupos de interesse das mais diversas tendèncias se organizando em torno dessa bandeira. Modismos e oportunismos à parte, creio que todos os cidadãos - principalmente os que vivem nos grandes centros urba. nos - deveriam se ocupar no sentido de preservar os rios, os lagos, as praias, as florestas, os animais e as montanhas. Caso isso nồo ocorra, como nos lembra Seattie neste belo livro lem que texto, ilustraçóes e capa se integram com harmonia). "E - firm da vida e o infcio de uma subvida" (p. 45).

Afrânio Mendes Catani Profassor na Facuidade de Educação da Universidade de São Pauto (USP). 